\title{
“The One Best Way?” Repensando a difusão do management e seus impactos em decisões na carreira acadêmica em administração
}

\author{
MÁRCIA de FreitAS DUARTE ${ }^{1}$ \\ ${ }^{1}$ Universidade de Fortaleza (UNIFOR) / Programa de Pós-graduAÇÃo EM AdMINISTRAÇÃo de EMPRESAS, ForTALEZA - CE, BRASIL
}

\section{Resumo}

Este artigo tem o objetivo de reforçar um debate com um caráter reflexivo, ao propor o (re)pensar e o questionar sobre aspectos relacionados à origem e à difusão do ensino e da pesquisa na área de Administração. Por meio de uma narrativa confessional, são apresentados o processo de desenvolvimento e legitimação do ensino e da pesquisa em Administração, tendo como base a literatura que trata do americanismo e do pós-colonialismo. Em seguida, argumenta-se que esse arcabouço teórico pode permitir melhor compreensão sobre a difusão e a aceitação mundial do modelo americano de produtividade e de ensino dessa disciplina (o management, the one best way), tornando-se algo naturalizado e com caráter universal, ao mesmo tempo em que reduzia iniciativas locais de gestão, diminuía contextos e silenciava atores potencialmente capazes de construir seu próprio campo de conhecimento relacionado à gestão. A partir daí, discute-se como a compreensão desse contexto em que o management emergiu pode reforçar certas reflexões sobre algumas das decisões inerentes à carreira acadêmica em Administração, bem como influenciar na postura e na prática do pesquisador e do docente, sendo este um tema essencial aos acadêmicos em formação ou aos que possuem alguma aspiração em cursar uma graduação ou pós-graduação nesta área.

Palavras-chave: Ensino e pesquisa em Administração. Carreira acadêmica. Pós-colonialismo. Americanismo.

\author{
"The One Best Way"? Rethinking management diffusion and its impacts in decisions on academic career in \\ the field
}

\begin{abstract}
This article proposes (re)thinking and questioning certain aspects of teaching and research on management to add a reflective nature to the debate. The study adopts a confessional discourse and presents the development and legitimization of management education and research, based on the literature on Americanism and post-colonialism. This theoretical framework may allow a better understanding of how management and teaching methods spread worldwide. The research suggests the existence of an American model of productivity and education (management, the one best way) becoming something natural and universal while reducing local management initiatives and silenced contexts and actors potentially able to build their own field of knowledge in management. The study also discusses that understanding the context in which the management emerged may reinforce certain reflections about some of the decisions related to an academic career in management, especially in terms of professor's and researcher's attitude and practice. These are essential themes for academics in training and for those who have any aspiration to become an academic or simply to pursue undergraduate and graduate degrees in management.
\end{abstract}

Keywords: Teaching and research in management. Academic career. Post-colonialism. Americanism.

\section{“The One Best Way"? Repensar la difusión del management y su impacto en la toma de decisiones en la carrera académica de Administración}

\section{Resumen}

Este artículo tiene como objetivo reforzar un debate reflexivo al proponer (re)pensar y cuestionar ciertos aspectos relacionados con el origen y la difusión de la enseñanza y la investigación en el área de Administración. Con este fin, mediante una narrativa confesional, se presenta el proceso de desarrollo y legitimación de la enseñanza y la investigación en la administración, basado en la literatura que trata sobre el americanismo y el poscolonialismo. Luego, se argumenta que dicho marco teórico puede permitir una mejor comprensión sobre la difusión y aceptación mundial del modelo estadounidense de productividad y enseñanza (el management, the one best way), convirtiéndose en algo naturalizado y universal, al tiempo que reduce las iniciativas locales de gestión, disminuye los contextos y silencia a los actores potencialmente capaces de construir su propio campo de conocimiento de gestión. A partir de esto, se discute cómo la comprensión de este contexto en el que surgió el management puede reforzar ciertas reflexiones sobre algunas de las decisiones inherentes a la carrera académica de Administración, así como influir en la postura y la práctica del investigador y del docente, un tema esencial para académicos en formación o para aquellos que aspiran ingresar a cursos de pregrado o posgrado en esta área.

Palabras clave: Enseñanza e investigación de Administración. Carrera académica. Poscolonialismo. Americanismo. 


\section{INTRODUÇÃO}

Há algum tempo, jamais cogitaria iniciar um texto acadêmico em primeira pessoa e tampouco relatando algumas de minhas experiências como aluna de um curso de graduação e também pós-graduanda em administração. Trata-se de uma ruptura e porque não dizer ousadia, no sentido de que, no fundo, acredito que só grandes pesquisadores e autores de uma determinada disciplina ou área de conhecimento tenham a liberdade e a maturidade de expressar-se assim tão livremente, sem as imposições de padrões amplamente aceitos, naturalizados e quase intransponíveis para aqueles que se propõem a promover ou até mesmo sugerir mudanças.

Porém, mesmo na minha condição de aprendiz e frente a uma possível rejeição (muitas, até o momento em que reescrevo esta versão!), opto aqui por fugir um pouco da estrutura e padrão acadêmicos predominantes, por acreditar que trabalhos e estudos devam, antes de tudo, fomentar discussões acerca de temas relevantes à área, trazendo contribuições e não apenas reproduzindo discursos e práticas.

Partindo da premissa de que "a análise do passado permite melhor observar o caráter ideológico das práticas e concepções prescritas no presente" (VIZEU, 2010, p. 46) este ensaio tem o objetivo de reforçar um debate com um caráter reflexivo, ao propor o (re)pensar e o questionar acerca de aspectos relacionados à origem e à difusão do ensino e pesquisa na área de administração. Por meio de uma narrativa confessional (VAN MAANEN, 1988), são apresentados o processo de desenvolvimento e legitimação do ensino e pesquisa em administração no Brasil, tendo como base a literatura que trata da colonialidade epistêmica, do americanismo e do pós-colonialismo. Também são utilizados conhecimentos relacionados a maneira como esta disciplina e sua forma de ensino foi sendo difundida e aceita mundialmente em seu modelo americano de produtividade e de ensino (o management - the one best way), tornando-se algo naturalizado e com caráter universal, ao mesmo tempo em que intimidava iniciativas locais de gestão, reduzindo contextos e silenciando atores potencialmente capazes de construir seu próprio campo de conhecimento acerca da gestão. A partir daí, discute-se como a compreensão deste contexto em que o management emergiu pode favorecer algumas decisões na carreira acadêmica em administração, sobretudo para os acadêmicos ainda em formação, como é meu o caso. Não me dedico à discussão sobre o que é conhecimento considerado "válido" ou ao reforço de polarizações, divergências e conflitos que residem na área da gestão. Longe disso. A ênfase aqui reside em apresentar e discutir como a construção e a difusão desses conhecimentos relativos à área da gestão é permeada por uma geopolítica formada por relações de poder, tema que embora ganhado destaque nos últimos anos (SERVA, 2017), ainda está longe de ser amplamente discutida em salas de aula e se refletir em pesquisas teóricas e empíricas. Não se trata da defesa de uma visão antieuropeia essencialista ou fundamentalista, mas sim de desenvolver e exercitar a reflexão crítica diante dos fundamentalismos, nacionalismos e colonialismo, os quais estão fortemente relacionados ao pensamento e práticas eurocêntricas, e diante do reducionismo e limitações intelectuais frequentemente associadas ao Terceiro Mundismo (GROSFOGUEL, 2007).

A narrativa confessional, tomada emprestada da escrita etnográfica, caracteriza-se pelo relato em primeira pessoa, por sugerir uma intimidade com os leitores, por desmistificar as práticas de pesquisa de campo, além de apresentar as vivências, experiências, reflexões e pontos de vista do pesquisador (VAN MAANEN, 1988). Não se trata de reivindicar a realização ou relato de uma auto-etnografia; apenas adotei o referido formato de escrita e narrativa para salientar que os relatos pessoais aqui mencionados atuam apenas como guia para a condução do texto e da discussão, por acreditar que algumas de minhas experiências, dúvidas, questionamentos e angústias possam ser também compartilhados pelos 654.843 matriculados no curso de graduação em Administração, conforme o Censo da Educação Superior de 2018 (Instituto Nacional de Estudos e Pesquisas Educacionais Anísio Teixeira (2019). Tampouco é pretensão de minha parte apresentar-me como exemplo ou modelo ou sugerir respostas prontas e definitivas para as questões aqui mencionadas. Se conseguir incitar algum tipo de questionamento ou inquietação em algum graduando em administração ou com aspiração em cursar tal faculdade ou mesmo em algum mestrando ou doutorando, fazendo-o refletir acerca desta carreira e as decisões inerentes a ela, já terei cumprido meu objetivo.

A presente pesquisa reúne uma literatura afiliada ao emergente campo da História da Administração e das Organizações (BOOTH e ROWLINSON, 2006), o qual considera as ideias, práticas e discursos da Administração como fenômenos históricos, sociais e geopolíticos (ALCADIPANI e BERTERO, 2014). Parte considerável dessas pesquisas se vale da história para construir narrativas do passado que contribuam para compreender quais os contextos sociais e políticos que possibilitaram certas possibilidades de desenvolvimento em lugar de outros (BARROS, ALCADIPANI e BERTERO, 2018). Esses estudos contribuem, 
portanto, para a legitimação das instituições, práticas e corpos de conhecimento contemporâneos (COOKE, 2003), pois permitem a compreensão de que o presente não é algo natural, mas, sim o resultado de ações e práticas específicas (JACQUES, 2006).

Sob o olhar da perspectiva histórica, este ensaio compartilha com Alcadipani e Bertero (2014) o pressuposto de que o objeto de análise somente pode ser compreendido dentro do contexto histórico nacional e internacional de sua época. Portanto, as organizações bem como conhecimento gerado sobre elas devem ser tratados como algo imerso em um contexto histórico-social que precisa ser investigado e analisado (MARCH, 2005). Embora a aproximação entre administração e história não seja recente, ela ainda não avançou substancialmente de forma a viabilizar seu potencial ontológico, epistemológico e metodológico (COSTA, BARROS e MARTINS, 2010). Tais esforços, ao descortinarem os processos de manipulação que se manifestam em todos os níveis da constituição do saber histórico e administrativo, ampliam as possibilidades de reflexão sobre a prática social dos pesquisadores, instigando-os a considerar novas fontes, novos problemas e novas abordagens, de forma a faze-los perceber que novos questionamentos tem o potencial de deslocar o foco de analise do exógeno para o local, contribuindo assim com o desenvolvimento de análises mais críticas sobre ideologias administrativas vigentes (COSTA, BARROS e MARTINS, 2010).

O artigo encontra-se estruturado em três seções, incluindo esta introdução. Na segunda seção, dividida em três momentos, apresento aspectos relativos ao desenvolvimento e legitimação do ensino e pesquisa em administração, tendo como base a literatura que trata do americanismo, perspectiva histórica sobre a difusão do ensino de administração e pós-colonialismo. Parto da premissa de que o acesso a este conteúdo e a reflexão proporcionada pelo mesmo pode contribuir para algumas das decisões inerentes à carreira acadêmica, bem como influenciar na postura e na prática do pesquisador e docente, sendo este um tema essencial aos acadêmicos em formação e aqueles que cogitam o ingresso na academia. Por fim, seguem as considerações finais, apresentadas numa reflexão acerca da carreira acadêmica, bem como alguns caminhos que vem sendo adotados por alguns pesquisadores brasileiros, tal como a perspectiva da decolonialidade.

\section{O QUE NOS É ENSINADO, COMO, POR QUEM E POR QUÊ}

"Você vai fazer vestibular para quê"? Responder esta questão é, por si só, um desafio e exercício de autoconhecimento. Quando afirmava meu desejo não tão consciente de prestar vestibular para Administração, ouvia perguntas como: "mas você vai administrar o quê?", "você é filha de empresários?", "tem planos de abrir uma empresa?", "tem capital pra isso?". Eu não tinha respostas para essas questões até mesmo por não saber exatamente do que se tratava a profissão de administrador, sua complexidade e, principalmente, sua amplitude de atuação.

Na primeira semana de aula, recordo-me da disciplina de Teoria Geral da Administração (TGA), a primeira em que teríamos a oportunidade de aprender sobre gestão, já que as demais pareciam para nós, "do alto de nossa ampla experiência de primeiro semestre", em nada aproximar-se do curso que havíamos escolhido. Tema da primeira aula de TGA: origens históricas da administração. Pelo que me recordo daquele dia, aprendemos sobre algumas civilizações antigas, uma breve apresentação de suas formas de organização, bem como a influência de organizações militares e da igreja católica na formação do que hoje conhecemos como Administração.

$\mathrm{Na}$ aula seguinte, um salto histórico foi realizado, sem que nós, alunos, considerássemos ou sequer questionássemos o porquê. O tema da segunda aula foi "Princípios da Administração Científica", quando aprendemos sobre um engenheiro chamado Frederick Winslow Taylor, considerado "pai da administração" e cuja doutrina denominada Scientific Management foi responsável pela adoção da administração sistemática nos Estados Unidos (EUA) e em outras partes do mundo, dando assim, um caráter mais científico a ela, ao disseminar a crença de que existe uma melhor maneira - the one best way - de se gerir.

Longe de questionar a relevância das contribuições de Frederick Taylor, faz-se necessário reconhecer que a Administração Científica não é o início da administração (ALCADIPANI, 2011a), embora seja um marco para tal disciplina (VIZEU, 2010). Se considerarmos que a realização de atividades como plantações, colheitas, lutas entre povos, construção de cidades ou manufatura de qualquer bem, por mais artesanal que seja, prescindem de alguma forma de gestão a ser desempenhada, é pouco provável que pensemos em qualquer tipo de sociedade na qual a atividade da gestão esteja ausente (STARBUCK, 2003; ALCADIPANI, 2011A). Mesmo em suas versões mais rudimentares, a gestão envolve planejar, reunir pessoas em torno de um objetivo específico, dividir tarefas e coordenar atividades, com vistas a fazer um grupo atingir objetivos específicos. 
Esses elementos foram cruciais para a construção de pirâmides e templos religiosos, guerras ou criação de reinos dominantes (ALCADIPANI e CALDAS, 2012). Sendo assim, quais seriam as razões para ensinar apenas uma visão limitada dessa disciplina, dessa atividade tão complexa? Por que considerar e aceitar essa perspectiva como verdade absoluta, correta e incontestável, eliminando do debate quaisquer outras possibilidades e alternativas? Quais seriam as origens das teorias, hoje naturalizadas, e aceitas como a forma correta de administrar? É possível ensinar alguém a administrar?

Penso ser no mínimo curioso que eu, e acredito que a maioria de meus colegas, tenhamos passado por toda a graduação sem que essas questões tivessem nos inquietado ou que não tivéssemos sido estimulados para que pudéssemos suscitá-las. Talvez por uma falha em minha formação enquanto bacharel, ou escolha da instituição na qual estudei, formação dos professores, matriz curricular, falta de curiosidade ou até por, em princípio, não haver espaços para questionamentos e reflexões em um curso tão pragmático como se propõe a ser uma graduação em Administração. Nas subseções a seguir, buscarei explorar e desenvolver reflexões sobre ensino e pesquisa em Administração e como essa perspectiva, única e verdadeira num primeiro momento, pode ser compreendida a partir de contextos socioeconômico, histórico e cultural, repercutindo até hoje na forma como ensinamos nossos alunos, desenvolvemos nossas pesquisas e nos questionamos enquanto acadêmicos desta área.

\section{A geopolítica de produção e difusão do conhecimento}

Mesmo que a administração, enquanto atividade humana, perca-se nas sombras dos séculos (STARBUCK, 2003; BERTERO, 2006; ALCADIPANI e CALDAS, 2012), é historicamente recente o esforço de torná-la um objeto de escolarização, sobretudo no interior das universidades, formando assim um conjunto de conhecimentos e habilidades que pode ser ensinado e aprendido (BERTERO, 2006). Esse corpo de conhecimentos, habilidades e técnicas norteadas pelos conceitos de eficácia e eficiência, controle e avaliações constantes, com vistas à maximização dos resultados, é o que hoje se conhece como management (BERTERO, 2006), entendido como gestão ensinada nos EUA (ALCADIPANI e BERTERO, 2014). Esse conjunto configurar-se-ia como os princípios da Administração enquanto ciência, os quais foram amplamente difundidos pelo mundo, como receita universal, neutra e verdadeira para se atingir elevados níveis de produtividade e consequente desenvolvimento econômico (ALCADIPANI e BERTERO, 2014). Mas antes de se debruçar sobre as particularidades acerca do desenvolvimento e consolidação da gestão americana, faz-se necessário dar alguns passos para trás para se avançar à frente, como sugere Czaniawska (2010). Esse recuo consiste em buscar compreender a forma que a influência americana pode ser interpretada como uma continuidade do fundamentalismo da modernidade eurocêntrica ou do eurocentrismo/ocidentalismo (GROSFOGUEL, 2012a, 2012b).

A imposição de um modelo ou de princípios de gestão tidos como naturais e incontestáveis pode ser compreendida a partir da noção de colonialidade epistêmica, caracterizada pela imposição de conhecimentos produzidos em uma "outra" realidade e que se sobrepõe às práticas e aos conhecimentos locais, resultando na subalternização destes (IBARRA-COLADO, 2006). Diferentemente do colonialismo, o qual se refere a um período histórico fixo e estabelecido arbitrariamente por analistas, a colonialidade se refere a uma estratégia de dominação baseada na distinção racial entre conquistadores e conquistados e na estrutura hierárquica correspondente de divisão de trabalho e de geopolítica de produção de conhecimento (FARIA e WANDERLEY, 2013). Um dos fortes elementos da colonialidade de poder é o encobrimento de conhecimentos e histórias locais pela episteme totalitária da modernidade eurocêntrica - uma epistemologia territorial e imperial que inventou e estabeleceu as categorias que distinguem racial e hierarquicamente pessoas e regiões (MIGNOLO, 2009). Essa colonialidade de poder como princípio e estratégia de dominação e controle persiste mesmo após o término do período de dominação pelo colonialismo europeu na África e Ásia.

Os paradigmas eurocêntricos hegemônicos que compuseram a filosofia e as ciências ocidentais nos últimos quinhentos anos apregoam um ponto de vista objetivo, universalista e neutro, no qual o sujeito que fala está sempre oculto, apagado da análise (GROSFOGUEL, 2011). No entanto, como nos lembra Haraway (1991), o conhecimento é sempre situado e incorporado. Reconhecer esse quadro dominante de geopolítica do conhecimento que sustenta a colonialidade permite uma mudança de foco daquilo que é enunciado para a enunciação (MIGNOLO, 2011), abrindo espaços para que passemos a questionar "quem e quando, por que e onde o conhecimento é gerado" (MIGNOLO, 2009, p. 4).

Diante desse debate referente à necessidade de compreensão do lugar de enunciação (MIGNOLO, 2011; GROSFOGUEL, 2011), retomo aqui à minha narrativa individual com o intuito de pôr em prática este exercício, deixando claro de onde parte o esforço acadêmico de desenvolver o presente artigo. A pesquisadora e "voz" nesse ensaio é uma brasileira, nordestina e na segunda metade de sua terceira década de vida na época em que a narrativa confessional foi elaborada; minha pele é parda, 
sou de classe social média-baixa e minha experiência com o doutorado foi realizada fora de minha cidade natal, vinculada a um estágio de docência fora do Brasil, em país de língua inglesa.

Ao desvincular a localização epistêmica étnica/racial/de gênero/sexual do sujeito que fala, a filosofia e as ciências ocidentais foram capazes de produzir um mito sobre um conhecimento universal verdadeiro que oculta quem está falando, bem como a sua localização geopolítica e os corpos políticos nas estruturas de poder/conhecimento colonial a partir das quais o sujeito fala (GROSFOGUEL, 2011, 2012). Sob esse olhar, em termos de produção e expansão de conhecimento/ciência, a modernidade eurocêntrica estabeleceu o que era considerado conhecimento "válido" e "moderno" daquilo que era produzido no resto do mundo, o "não moderno", associado à barbárie, selvageria e primitivismo (SANTOS, NUNES e MENESES, 2008). Nesse contexto, as ciências sociais, no século XIX, na Europa, terminaram por estabelecer para o resto do mundo o que é política, o que é sociedade, e o que é economia, e produziram teorias para a prática e avaliação desses âmbitos sob a perspectiva do eurocentrismo (WALLERSTEIN, 1997).

Ocultando a localização do sujeito da enunciação, a expansão e o domínio colonial europeu e euro-americano conseguiram assim construir uma hierarquia de conhecimento superior e inferior e, portanto, de pessoas superiores e inferiores em todo o mundo (GROSFOGUEL, 2011). Historicamente, isso permitiu ao "homem ocidental" representar seu conhecimento como o único capaz de alcançar uma consciência universal, e rejeitar o conhecimento não ocidental como particularista e, portanto, incapaz de alcançar a universalidade (GROSFOGUEL, 2011). Como consequência, os diferentes tipos de saberes ao redor do mundo foram eliminados, subalternizados ou reformados pelo conhecimento científico (MIGNOLO, 2011). Como explorarei mais adiante, a história se repetiu ou foi continuada no âmbito da cientificação da gestão nos EUA, a qual seguiu e reforçou o desenho da ciência moderna eurocêntrica (GROSFOGUEL, 2012a, 2012b). Mas como assim os Estados Unidos passaram a assumir esse protagonismo em relação à construção e difusão do conhecimento científico em gestão/administração?

\section{Os EUA e seu protagonismo no conhecimento científico em gestão}

Conforme Khurana (2007), a emergência da profissão de gestor ocorreu no momento em que as grandes corporações americanas surgiram, demandando alguém que detivesse o seu comando. Um novo ator chamado gestor (manager), mesmo não sendo proprietário ou trabalhador, passou a realizar uma atividade que, embora não fosse tão visível e tangível quanto outras tarefas, foi crucial no desenvolvimento em grande escala das corporações, visto que passou a realizar funções, tarefas e autoridade antes exercidas por empreendedores ou pessoas que haviam dado início aos negócios, formando assim, uma "mão visível" em um novo sistema de capitalismo gerencial, contribuindo para que o Management viesse a se tornar uma das mais poderosas, embora invisível, instituições americanas. Invisível não no sentido de estar distante do olhar público, mas pelo fato de ser aceita e tida como certa, além de ser altamente influente e penetrante na sociedade.

A profissionalização e legitimação da profissão de gestor e a criação das escolas de negócio de base universitária surgiriam como atores institucionais que cumpririam o papel de legitimar este grupo de profissionais que reclamavam para si um corpo de conhecimento. A história das escolas de negócio representa esse projeto de profissionalização iniciado com a fundação da Wharton School, na Universidade da Pensilvânia, em 1881, e que permanece até o presente em múltiplas instituições e países. Emergiram com o intuito não apenas de preparar futuros gestores, mas também para atuar como importantes veículos de um esforço para transformar a gestão, vista antes como uma ocupação incipiente, em uma atividade profissional legítima, sendo os gestores os profissionais que dominariam um conjunto de conhecimentos voltados à gestão das organizações americanas (KHURANA, 2007).

No entanto, fora do contexto norte-americano, algumas iniciativas de escolas de comércio e negócios, como ocorreu na França e Itália (KIPPING, ÜSDIKEN e PUIG, 2004; ÜSDIKEN, 2004a) e na Alemanha (KIESER, 2004; ÜSDIKEN, 2004A), já haviam sido desenvolvidas antes e contemporaneamente à criação das primeiras escolas norte-americanas. Mas mesmo nos casos em que se buscou preservar algumas características de modelos locais e anteriores mesclando-os com o norte-americano sob a forma de hibridismos (FRENKEL e SHENHAV, 2003; ALCADIPANI e BERTERO, 2014), é inegável a influência do último sobre os primeiros, de modo que, se compreendermos a difusão do management como um projeto, podemos afirmar que este, de fato, foi bem-sucedido. O que ainda raramente questionamos é quem foram os favorecidos e quais as repercussões desse fato. A própria ausência de reflexões e questionamentos parece ser um dos aspectos inerentes ao projeto.

Mas como essas iniciativas anteriores e contemporâneas foram silenciadas e consideradas insuficientes ou capazes de interferir no que hoje conhecemos como management, uma criação predominantemente norte-americana? O management 
norte-americano ganhou proeminência internacional (ALCADIPANI e BERTERO, 2014) sendo possivelmente o primeiro produto a ser universalizado. Tal fenômeno pode ser compreendido sob a lente conceitual do americanismo ou americanização, processo deliberado e consciente no qual elementos e valores básicos da cultura norte-americana foram difundidos para outros países, como resultado da hegemonia política, econômica e militar dos EUA (GERSTLE, 1989; TOTA, 2000). Não é coincidência que a consolidação do ensino de Administração de empresas tenha ocorrido no mesmo momento em que se deu o estabelecimento dos EUA como superpotência do século XX (BERTERO, 2006).

Enquanto processo, a americanização contou com a participação direta do Estado e de fundações norte-americanas, com o intuito de impor a hegemonia dos EUA e descartar modelos e modos alternativos de se pensar, ensinar e praticar gestão (ALCADIPANI e BERTERO, 2014). Estes esforços foram intensificados ao fim da Segunda Guerra Mundial, quando, após a queda do Nazismo e Fascismo, duas grandes potências, os EUA e a União das Repúblicas Socialistas Soviéticas, encontraram-se na disputa pela hegemonia mundial (ALCADIPANI e BERTERO, 2012), na chamada Guerra Fria, fase compreendida entre 1945 1989/1990 e caracterizada pela disputa militar, ideológica e econômica entre esses dois países, afetando diretamente boa parte das nações do globo, inclusive nos campos acadêmicos (WESTWOOD e JACK, 2008). Esse ambiente político e ideológico inerente à Guerra Fria foi crucial do desenvolvimento das teorias e da difusão do ensino de Administração (KELLEY, MILLS e COOKE, 2006), pois influenciou o desenvolvimento e a institucionalização de saberes administrativos rigorosamente alinhados aos valores norte-americanos (MCLAREN e MILLS, 2008).

Na concepção do Governo norte-americano, na tentativa de impedir o avanço do comunismo, era preciso convencer os países europeus de que os EUA haviam se desenvolvido nos campos das artes e ciências, e também mostrar aos países do Terceiro Mundo (mais pobres) que o referido país se mostrava preocupado com a pobreza e o subdesenvolvimento. Um dos pontos deste discurso desenvolvimentista que norteou a política externa norte-americana referia-se a um novo e ousado programa, cujo objetivo era tornar os benefícios do avanço científico e progresso econômico americanos disponíveis para o desenvolvimento e crescimento econômico de áreas subdesenvolvidas (KANBUR, 2003). Ao mesmo tempo em que levaria prosperidade e desenvolvimento para várias regiões do mundo, as quais passariam a seguir os preceitos, ideais e valores defendidos pelos EUA, este programa também afastaria a ameaça comunista destes lugares (WESTWOOD e JACK, 2008). Concomitantemente, o objetivo da política externa desenvolvimentista norte-americana ia ao encontro dos interesses de várias nações, as quais vislumbravam no modelo de produtividade norte-americano a possibilidade de atingir o tão sonhado desenvolvimento (TOTA, 2000; MIR, MIR e SRINIVAS, 2004), e também de países europeus, diante da necessidade de erguer-se economicamente após a Segunda Guerra (KIESER, 2004) e/ou expandir seus negócios (FRENKEL e SHENAV, 2003; TIRATSOO, 2004; KIPPING, ÜSDIKEN e PUIG, 2004).

No entanto, essa assistência técnica e financeira oriunda de algumas instituições norte-americanas como a agência governamental United States Agency for International Development (ESCOBAR, 1988; ALCADIPANI e ROSA, 2011), a Organização do Tratado do Atlântico Norte (CLARK, 2005) e a Fundação Ford (MIR, MIR e SRINIVAS, 2004; TIRATSOO, 2004; WETSWOOD e JACK, 2008; ALCADIPANI e ROSA, 2011), estava condicionada à adoção da economia de mercado, do sistema sociocultural dos EUA e particularmente dos modelos norte-americanos nas empresas de vários países (disseminação da gestão, marketing e técnicas de produção que caracterizavam o modelo de gestão dos EUA) sob a crença de que os EUA não teriam chegado tão longe sem a dinamicidade, a inovação e o modelo de gestão de suas empresas, os quais geraram produtos, bens e serviços para um suposto bem-estar geral da sociedade por meio da disseminação de conhecimento e técnicas desenvolvidos naquele país. Ao serem patrocinadas pelo Governo norte-americano e auxiliadas com o crescente investimento direto estrangeiro das multinacionais norte-americanas, essas instituições exerceram grande influência na transferência e difusão da gestão, marketing e técnicas de produção norte-americanas, pois enfatizaram o profissionalismo desse modelo de gestão, bem como as suas capacidades organizacionais e estruturas de produção. A intenção, portanto, residia em gerar um capitalismo gerencial competitivo, característico do sistema de negócios dos EUA (CLARK, 2005). Formava-se o cenário no qual a Administração à americana - ou managerialism Foster, Mills e Mills (2014), passou a ser ativamente exportada como estratégia para fomentar o desenvolvimento econômico e distanciar a ameaça do comunismo soviético (KIPPING, ÜSDIKEM e PUIG, 2004; KIPPING, ENGWALL e ÜSDIKEM, 2008).

Assim, foram disseminados os princípios e modelos de gestão e ensino de Administração nos moldes norte-americanos, principalmente na Europa Ocidental e no Japão (FRENKEL e SHENHAV, 2003; CLARK 2005). Alguns autores já dedicaram especial atenção à maneira como este processo ocorreu em diferentes países como Alemanha (KIESER, 2004), Reino Unido (TIRATSOO, 2004), França, Espanha e Itália (KIPPING, ÜSDIKEN e PUIG, 2004), Suécia, Finlândia, Dinamarca e Noruega (ENGWALL, 2004) 
e Turquia (ÜSDIKEN e ÇETIN, 2001; ÜSDIKEN, 2004b), Índia (SRINIVAS, 2009; MIR, MIR e SRINIVAS, 2004) e Israel (FRENKEL e SHENHAV, 2003). A influência norte-americana também se fez presente na América Latina. Na Argentina, por exemplo, o primeiro curso de graduação em Management foi criado em 1958 na Universidade de Buenos Aires (GANTMAN e RODRIGUES, 2008).

No contexto brasileiro, a influência norte-americana é percebida nas missões de assistência (BERTERO, 2006; ALCADIPANI e BERTERO, 2012) de criação da Escola de Administração de Empresas de São Paulo, da Fundação Getulio Vargas - FGV EAESP (ALCADIPANI e BERTERO, 2012, 2014), da Faculdade de Ciências Econômicas da Universidade Federal de Minas Gerais (Barros, 2014); da Escola Brasileira de Administração Pública e de Empresas da Fundação Getulio Vargas (COELHO e NICOLINI, 2014) e do Departamento de Administração da Faculdade de Economia e Administração da Universidade de São Paulo (VALE, 2012). Embora não tenham sido as primeiras iniciativas de implantação de escolas de gestão no Brasil, visto que a Escola Superior de Negócios (ESAN) foi a pioneira (BERTERO, 2006), foram as instituições citadas que ganharam proeminência com o modelo de ensino de Administração norte-americano adotado e foram até mesmo utilizadas como base para o estabelecimento de cursos em outras instituições no país, como a Universidade Federal da Bahia e a Universidade Federal do Rio Grande do Sul (BARROS, ALCADIPANI e BERTERO, 2018). Nos casos mencionados, a interferência norte-americana pôde ser percebida, além da ajuda financeira, na adoção de materiais didáticos provenientes dos EUA, do treinamento de professores brasileiros em instituições norte-americanas, na utilização do método de casos e da adoção de grades curriculares nos moldes norte-americanos (BERTERO, 2006).

Há que se ressaltar, contudo, que a adoção do modelo gerencialista e produtivista norte-americano não ocorreu sem resistências ou mesclas com formas de gestão e sistemas de ensino endógenos. A FGV EAESP, por exemplo, mostra-se como uma instituição híbrida, pois não era similar nem às escolas brasileiras de Ciências Sociais, Contabilidade e Direito, que se ocupavam de tópicos ligados à Administração, nem a uma escola norte-americana de Administração de Negócios. Seu resultado foi diferente e inédito, pois mesmo manifestando características de várias organizações que a teriam originado, ela é de uma individualidade absolutamente distinta de seus geradores (ALCADIPANI e BERTERO, 2014). Na perspectiva dos Estudos Organizacionais Críticos (EOC), Paes de Paula, Maranhão, Barreto et al. (2010) argumentam que os trabalhos de Alberto Guerreiro Ramos, Maurício Tragtenberg e Fernando Prestes Motta, suas obras e estudos nelas inspirados remetem à existência de EOC no Brasil antes da emergência dessa corrente na Europa e nos EUA. A ideia central é que essa antecedência constitui uma tradição, que é autônoma porque a base teórica e epistemológica utilizada por esses pensadores críticos é distinta, e mesmo oposta ao pós-estruturalismo predominante no contexto internacional, uma vez que é humanista radical e se baseia no Marxismo, no Anarquismo, na Teoria Crítica e no Existencialismo. Dentro das tentativas de se resgatar a autonomia de autores brasileiros acerca da gestão, vale ressaltar o número temático do Cadernos EBAPE.BR, cujo objetivo era explorar o status da tradição autônoma dos EOC, fundamentada na influência dos pensadores supracitados.

No entanto, mesmo que tenha havido algum tipo de hibridização (FRENKEL e SHENHAV, 2003; KIPPING e ÜSDIKEN, PUIG, 2004), migração de um modelo estrangeiro para outro (ENGWALL, 2004) ou a emergência de modelos alternativos que se oporiam à americanização (SRINIVAS, 2009), não há como negar que o americanismo alterou a cultura e o modo de vida em diversos países, fato que se refletiu nas funções de gestão, no sistema de ensino e nas formas de se construir conhecimento, na forma de pesquisas.

Podemos assim compreender que a difusão do modelo gerencialista e do ensino de Administração norte-americanos foram, portanto, favorecidos por um conjunto de atores institucionais e seus respectivos interesses (KHURANA, 2007; WESTWOOD e JACK, 2008). O Governo norte-americano (difusão de suas empresas, busca por novos mercados, expansão de seus modelos), os governos locais (busca pelo desenvolvimento) e a comodidade de se adotar um modelo já consolidado (o norte-americano), ancorado no discurso científico neutro de que esta era a forma correta de se administrar porque tinha possibilitado os EUA a atingirem aquele nível de desenvolvimento, contribuíram na consolidação e difusão da gestão desenvolvida nos EUA. Assim, o fato de o conhecimento sobre gestão ter se difundido no mundo como uma instituição predominantemente norte-americana (KHURANA, 2007) não é um mero acaso.

Diante da elucidação proporcionada por esta breve perspectiva histórica, creio ser inevitável o questionamento acerca de como essas construções afetaram e ainda afetam o ensino e a pesquisa em Administração. Tal reflexão, como veremos logo mais, pode lançar luz sobre alguns questionamentos para mestrandos e doutorandos cuja carreira acadêmica está em construção. 


\section{Nós, como outros}

Na transição para a pós-graduação, me deparei com uma sensação de não adequação aos modelos esperados pelas organizações. Em parte, essa inquietação provinha de minhas experiências como bolsista de pesquisa nos últimos anos da faculdade. Aliás, a possibilidade de ingressar na carreira acadêmica neste campo foi a mim apresentada tarde demais, apenas nos últimos semestres do curso, ao contrário do que acontece em outras áreas, dentro da mesma universidade.

O período da pós-graduação (mestrado e doutorado) foi (ainda está sendo) acompanhado de questionamentos mais profundos quanto à carreira acadêmica e uma série de mudanças quanto à vida pessoal, tão comuns na vida de pós-graduandos. Confissões à parte, quero frisar aqui o quanto o ensino recebido na graduação e a negação de possibilidades e alternativas pode contribuir na reflexão e nas possíveis decisões para aqueles que optaram pela carreira acadêmica. Assim, se aprendemos (absorvemos) que há um suposto modelo correto de se gerir e de se fazer pesquisa, quais seriam os impactos deste fato para o desenvolvimento de um pós-graduando?

Conforme seção anterior, o ensino em Administração constitui também um discurso e, como tal, certas condições foram necessárias à sua emergência, circunstâncias que moldam seus contornos e determinam seu espaço nos sistemas de poder do conhecimento (WESTWOOD e JACK, 2008). A disseminação do mainstream management cria uma realidade na qual certos interesses são privilegiados em detrimento de outros (MIR, 2003). Nesta construção, a Administração é compreendida como um discurso ideológico, neutro e correto, ancorado em métodos de pesquisa científicos que representam a "verdade", por serem considerados confiáveis e válidos (MIR, 2003). Quaisquer outras formas que não se enquadrem neste modelo são tidas como falsas, pouco eficazes, amadoras e inferiores.

No contexto da gestão e mais especificamente dos Estudos Organizacionais, a perspectiva pós-colonialista, ao concentrar-se na análise de como os corpos de conhecimento ocidentais foram constituídos, apresenta-se como uma abordagem teórica capaz de ampliar a compreensão quanto ao contexto histórico e cultural no qual a americanização dos processos de gestão ocorreu (FRENKEL e SHENHAV, 2003). Sob tal lente de análise, nos aproximamos do fenômeno descrito por Edward Said como Orientalismo, processo descrito como uma visão distorcida do Oriente, criada pelo Ocidente, a partir de seus amplos interesses de colonizar aquela região, representando assim um estilo de pensamento ocidental voltado para a dominação, reestruturação e desejo de ter autoridade sobre o Oriente (SAID, 1979). Difundir discursos ocidentais e modelos científicos nas colônias reflete, dessa maneira, uma prática colonial direcionada a fazer com que a população colonizada aceitasse, sem grandes resistências, a superioridade ocidental (FRENKEL e SHENHAV, 2003). Ao serem socializados no interior de um sistema colonial de educação e burocratização, os colonizados internalizam um "ponto de vista e desenvolvem um 'eu' colonizado", bloqueando tentativas de resistência ao poder colonizador (MITCHELL, 1988), caracterizando-se assim o processo de colonialidade (MIGNOLO, 2009; FARIA e WANDERLEY, 2013), tal como descrito anteriormente, embora aqui estejamos nos atendo especificamente ao campo da gestão.

Ao compreender essa desigualdade de relações na construção e difusão do conhecimento, na medida em que este processo se consolida a partir de discursos voltados à construção do "outro" (Oriente, nativos, Terceiro Mundo, subdesenvolvidos) como "subalterno", incapaz de produzir seu próprio conhecimento e práticas, justificando assim a intervenção, ação e supremacia de sujeitos compreendidos como superiores, a difusão do Management pode ser entendida como um processo de "outrificação" (IBARRA-COLADO, 2006; ALCADIPANI e ROSA, 2010), pois reduziu ou construiu como inferiores as iniciativas endógenas de práticas de gestão, de maneiras ou formas alternativas de ensiná-las e de se pesquisá-las. Os estudos voltados para a gestão e organizações assumiram assim uma fachada unidimensional, sendo uma disciplina construída a partir da colonização epistemológica oriunda dos EUA (IBARRA-COLADO, 2006; ALCADIPANI e ROSA, 2011). Os livros-texto de gestão raramente questionam essa posição epistemológica, essa ordem social criada pelo discurso do management; eles a neutralizam, fazendo-a parecer o resultado lógico de um processo de desenvolvimento histórico, uma verdade auto evidente (MIR, 2003). A prova desta naturalização é que, como estudantes, gestores e até mesmo docentes e pesquisadores, pouco sabemos sobre estes modelos ou sequer consideramos a sua existência, posto que o foco se volta para o racionalismo, a produção em larga escala, inclusive do conhecimento (ALCADIPANI, 2011a, PAES de PAULA, 2015).

Nos esforços de pesquisas, esse discurso também se faz fortemente presente. Há quem defenda que hospitais, Organizações Não Governamentais, organizações filantrópicas, religiosas, escolas e universidades devam seguir normas e preceitos da gestão tradicional e, como consequência, a produção de conhecimentos, o processo de cuidar das pessoas e luta por causas humanas podem seguir as mesmas regras de gestão da produção em série (ALCADIPANI, 2011a). Na esfera pessoal e profissional, somos 
compelidos a gerir nossas carreiras, nossas agendas, planejar horários das atividades dos filhos e um sem-fim de atividades. Surgem assim as mais diversas consultorias em áreas diversas e a crescente leva de personal "alguma coisa", tudo sob a lógica da busca de uma melhor maneira que possibilite a maximização de resultados, a produtividade.

Entre os acadêmicos, essa lógica do produtivismo ou "mcdonaldização" do ensino se faz presente na transformação de cursos em produtos, no acréscimo de cursos enlatados, na ausência de reflexões nas salas de aulas, na busca para ensinar o que supostamente seria o que melhor funciona, no uso de materiais didáticos rasos, na transformação do aluno em cliente, na proliferação das formas de avaliação de desempenho de professores similares às que ocorrem nas empresas e na quantificação da produção acadêmica (ALCADIPANI e BRESLER, 1999). Essa lógica produtivista transforma produção acadêmica em sinônimo de pontuação, e pode pôr em cheque até a própria ética acadêmica e a consequente possível criação de uma geração de acadêmicos voltados mais para a publicação (em termos quantitativos) do que para a reflexão e construção de conhecimento aliado ao amadurecimento e desenvolvimento intelectuais (ALCADIPANI, 2011a).

Outros reflexos do processo de construção desta realidade são sutis, mas perceptíveis, e se referem ao que é pesquisado, estudado e difundido, e consequentemente aceito como verdade, deixando às margens outras alternativas desenvolvidas em outros contextos e por outros atores. Questões relativas às raças e às minorias são um exemplo: em grande parte dos livros anglo-saxônicos de gestão, não somente os gestores são pensados e entendidos como racionais, mas também retratados como, principalmente, pessoas brancas e do sexo masculino (MILLS e HATFIELD, 1999), excluindo da "gestão ideal", outras etnias e as mulheres. Temos, assim, a naturalização de um gênero (masculino), uma raça (branca), uma determinada visão de sucesso, a universalização de técnicas e modelos de gestão independentes do contexto, a redução de outras realidades e a importação de agendas e métodos de pesquisa.

Os aspectos mencionados permitem-nos compreender um mundo epistemologicamente diverso e múltiplo, ao mesmo tempo em que representa uma forma de denunciar a colonização na construção do conhecimento, na medida em que desnaturaliza o management, ao explorarmos sua diversidade em vários contextos do planeta (ALCADIPANI e ROSA, 2011). Isso favorece a nossa compreensão do quanto o ensino que recebemos na graduação e a negação de possibilidades e alternativas pode interferir na reflexão e nas possíveis decisões enfrentadas por aqueles que optaram pela carreira acadêmica em Administração. E se estamos cegos de tanto aceitar um modelo específico de gestão e como explorá-la enquanto ciência, faz-se necessário questionar o impacto e a relevância desses padrões, sobretudo na condução e na construção de uma carreira voltada para a pesquisa e o ensino.

Como acadêmica em formação, creio que tal questionamento e reflexão é um imperativo, embora reconheça que esta é uma percepção e crença não compartilhadas por outros colegas, os quais a julgam desnecessária, numa espécie de conformismo que se traduz mais ou menos assim: as regras estão aí, cabe a nós jogarmos o jogo, dançar conforme a música. Concordo que os padrões já estão estabelecidos, mas o desinteresse em sequer conhecer como estes foram construídos e como exercem influências sobre nosso exercício acadêmico e outras esferas da vida, talvez possa ser considerado uma lacuna no perfil de um(a) aspirante a(à) acadêmico(a).

\section{REFLEXÕES SOBRE A CARREIRA ACADÊMICA EM ADMINISTRAÇÃO}

Procurei destacar, a partir da literatura voltada à compreensão da americanização e da abordagem pós-colonialista, alguns questionamentos com base em minha experiência como aluna e acadêmica em formação, compartilhando algumas das reflexões e indagações surgidas quanto à carreira acadêmica, na medida em que vou me preparando para ela. Dentre estas, incluem-se a necessidade de conhecer as origens e o contexto histórico no qual foram formuladas e disseminadas as teorias, modelos de gestão e práticas de pesquisa hoje tomadas como certas e legítimas, a relevância deste conhecimento e a compreensão dos impactos desta realidade construída no momento das decisões quanto aos interesses de pesquisa, algumas das consequências desta ordem social na qualidade de ensino de Administração e a invasão da lógica e do modelo produtivista, o qual não se restringiu às corporações.

Diante do exposto, questiono-me sobre como me relaciono com tais questões: contribuirei para a continuidade dessa realidade legitimada e naturalizada? Há formas de escape? Quais seriam as posturas alternativas enquanto pesquisadora e docente? Estaria eu fazendo parte de uma geração medíocre de acadêmicos em (de)formação que visa apenas preencher um currículo com publicações sobre temas que pouco despertam meu interesse e quase nada trazem de novo em termos de conhecimento? 
(Re)conhecer as tensões do management e da produção de conhecimento nesta área como um projeto imposto, no qual nós não somos o centro e sim a margem, "os outros" já pode ser um início promissor (IBARRA-COLADO, 2006) ao possibilitar a percepção, por exemplo, de que o trabalho de estudiosos e pesquisadores organizacionais não inseridos no Ocidente pouco aparecem nas mais prestigiadas revistas científicas do campo, as quais pertencem ao "centro" institucionalizado da gestão e da ciência organizacional (ALCADIPANI, KHAN, GANTMAN et al., 2012). Deparar-se com esses questionamentos, reflexões e contextos de construção dos conhecimentos foi (ainda é!) uma tarefa incômoda, pois significa abandonar um espaço de conforto das falsas práticas de falsificação do conhecimento, as quais são provenientes do centro, e nos arriscarmos a "nos compreender como os outros", no sentido de fazer emergir outras realidades que têm sido sufocadas, escondidas e reduzidas (IBARRA-COLADO, 2006). Nossos esforços assim podem ser voltar para o fato de que há vida acadêmica para além da visão hegemônica, tanto em termos de conceitos teóricos em gestão como em práticas organizacionais (ALCADIPANI, KHAN, GANTMAN et al., 2012).

É necessário reforçar que essa crítica ao colonialismo presente na ciência contemporânea vem se fortalecendo não somente no Brasil, mas também em outros países da América Latina (SERVA, 2017). Pesquisadores brasileiros como Misoczky e Imasato (2014) afirmam que o campo euro-estadunidense da administração/gestão deve então ser abandonado integralmente e substituído por alternativas locais. Esta crítica abre espaços para novas construções teóricas originadas da cooperação Sul-Sul que implicam necessariamente formulações epistemológicas compatíveis com os posicionamentos políticos pregados por essa corrente (SERVA, 2017). Nesse sentido, para além da perspectiva pós-colonial aqui explorada, destacam-se também os esforços da perspectiva decolonial, a qual também suscita o engajamento de autores latino-americanos e brasileiros (FARIA, IBARRA-COLADO e GUEDES, 2010) ao defender a necessidade de descolonizar o campo de gestão por meio de teorizações desenvolvidas a partir de perspectivas "outras" (MIGNOLO, 2011), numa espécie de pluriversalidade transmoderna, a qual transcenderia assim a modernidade eurocêntrica ao não propor a substituição desta por outra modernidade, mas, sim, a construção de um mundo em que diversos mundos e conhecimentos possam coexistir (MIGNOLO, 2011; FARIA e WANDERLEY, 2013).

No campo da administração/gestão, a decolonialidade se manifesta em subáreas de pesquisa mais fronteiriças como os estudos organizacionais e estudos críticos em gestão (IBARRA-COLADO, 2006; ALCADIPANI, KHAN, GANTMAN et al., 2012; WANDERLEY e FARIA, 2012; FARIA e ABDALLA, 2014). Eis alguns exemplos: Alcadipani e Faria (2014), a partir da abordagem decolonial, analisam em que medida o periódico Critical Perspectives on International Business desafia a hegemonia anglo-saxônica na área de negócios internacionais; Abdalla (2014) problematiza a relevância da opção decolonial na investigação de processos de proteção social em territórios historicamente subalternizados e subsocializados no Brasil; e Faria e Wanderley (2013) engajam-se na opção decolonial para analisar a trajetória de marginalização de organizações familiares no campo da gestão e, em especial, em gestão estratégica. Por último, destaco aqui o esforço empreendido por Abdalla e Faria (2017), ao proporem "a co-construção de uma agenda transcosmopolita (nem cosmopolitanismo eurocêntrico nem regionalismo, continentalismo ou nacionalismo) em administração/gestão no e a partir do Brasil, a qual possa promover conhecimentos e práticas informados pela opção decolonial, como alternativa à radicalização da pobreza e da desigualdade geoepistêmica no campo. Tal agenda se baseia em três âmbitos interligados: acadêmico, educacional e social. Nestes últimos, a construção de conhecimentos alinhados às realidades locais é a mola mestra para novas posturas epistemológicas na elaboração científica no campo da administração.

Acredito que os âmbitos acadêmico, educacional e social explorados por Abdalla e Faria (2017) estejam presentes nesse meu esforço ensaístico, pelas próprias características da narrativa confessional a partir de minha breve experiência. Enquanto docente, talvez uma postura que se aproxime desta proposta seja o incentivo à capacidade crítica dos discentes, com vistas a desenvolver um olhar mais profundo da formação do corpo de conhecimento da Administração e como este se consolidou. Pergunto-me se, enquanto graduanda, eu não teria absorvido melhor os fundamentos do pensamento administrativo se o tivesse compreendido como o resultado de uma construção em meio a um contexto que favoreceu a disseminação e a preponderância de uma forma específica de management em detrimento de outras, que nem cheguei a cogitar que existiam. É ingenuidade também crer que todos os alunos de um curso massificado como administração tenham esse interesse. Na busca por diplomas, muitos alunos almejam apenas um acréscimo de salário, um título para prestar um concurso, uma graduação "mais fácil" ou "indolor". Afinal, de quantos CEOs uma grande empresa precisa? A própria estrutura de ensino, as instituições, o mercado editorial e a má formação de professores contribuem para que a ordem se mantenha e que os alunos sequer desenvolvem a capacidade crítica e de pensar, essencial à carreira de gestor (ALCADIPANI, 2011b). 
Como pesquisadora, o exercício de se "compreender como outro" se espelha, por exemplo, na reflexão de qual seria o sentido em se fazer pós-graduação e na definição de uma agenda de pesquisa. Questionamentos quanto à opção (ou imposição?) por produção de artigos em massa, os conluios e articulações visando acréscimo de citações e produções, a ética na elaboração de estudos, a definição de autoria, a abertura para métodos e temas de pesquisa fora do mainstream e os rígidos e aparentes intransponíveis padrões para publicação são temas a serem (re)pensados por nós, enquanto acadêmicos em formação.

Reconhecendo a invasão do gerencialismo e do modelo produtivista na academia, seremos munidos de conhecimento e de uma perspectiva crítica com as quais seremos postos a nos questionar o que vale mais: produção em larga escala de artigos ou preparação, leitura, amadurecimento de conhecimento com vistas a, de fato, escrever dissertações e teses com conteúdo relevante e não apenas como uma mera reprodução e formalidade para a obtenção de um título? Ao mesmo tempo, pergunto-me se é possível resistir a essa lógica. Supondo que as regras do jogo já estavam definidas antes mesmo de ingressar na faculdade ou cogitar a carreira docente, que alternativas restam? Como resistir, se ao meu lado, colegas se submetem a esta lógica e se isto, no futuro, isso pode pesar contra mim? É importante discutir também o âmbito institucional da área, pois sabemos que programas de stricto sensu em administração/gestão no Brasil e instituições de regulação e fomento têm endossado e reforçado a lógica, paradigmas e perspectivas dominantes, em busca de inclusão, prestígio, acumulação ou obtenção de recursos financeiros e posições nos rankings supostamente globais (BERTERO, ALCADIPANI, CABRAL et al., 2013). O fato é que o peso é caro demais para ser pago por poucos indivíduos, devendo ser pago pela coletividade acadêmica (ALCADIPANI, 2011b).

Percebo essas decisões como difíceis, incômodas e requerentes de exercícios de reflexividade. Reproduzir e não questionar parece ser menos problemático? Talvez. Mas reconheçamos também que todas essas escolhas estão permeadas por alguns ingredientes pessoais associados a experiências específicas, histórias de vida, posições paradigmáticas etc. Preciso esclarecer ainda que o presente artigo e sua autora não têm a proposição de ajuizar ou classificar quem não opta por posturas não críticas ou aqueles para os quais os temas debatidos não se mostram como problemáticos. Pelo contrário. Advogo apenas em favor da multiplicidade de olhares e perspectivas, da necessidade de produzir e construir teorizações a partir de outros olhares não europeus/norte-americanos e a desnaturalização de uma gestão tida como neutra e universal. Suscitar esse debate em jovens acadêmicos e contribuir com as discussões sobre as posturas pós-colonialistas e decoloniais e como estas talvez possam ser trabalhadas didaticamente em salas de aula e em grupos de estudo são alguns dos fins com os quais este ensaio pode contribuir. Com a consciência do rigor científico e respeito à produção de conhecimento anterior e legitimada, destaco que a liberdade na condução de estudos e pesquisas é primordial ao desenvolvimento e avanço do campo da Administração como ciência. Reitero que liberdade aqui não é sinônimo de ausência de rigor metodológico na condução de pesquisas e construção de conhecimento, tampouco da ausência de ética e profissionalismo.

Na crença de que esta inquietação não é exclusividade minha, uma possibilidade de escape pode ser deslumbrada na compreensão da existência não de um Management mas de Managements, tal como aponta a perspectiva decolonial ao propor a coexistência de diversos mundos e conhecimentos: "[...] você percebe que sua inferioridade é uma ficção criada para dominá-lo(a), e você não quer assimilar ou aceitar resignadamente a má-sorte de ter nascido igual a todos os seres humanos, mas ter perdido essa igualdade logo após o nascimento, por causa do local onde isso ocorreu (MIGNOLO, 2013, p. 135). Há, assim, pluralidades e realidades além desta que nos foi imposta, sendo possível elaborar agendas de pesquisa próprias, com vistas a abordar questões locais, endógenas e, consequentemente, voltadas para a desconstrução de uma realidade, o que implica a aceitação e compreensão de realidades, nas quais há muito o que ser considerado e pesquisado.

Desse modo, partiríamos para uma concepção na qual nós, enquanto "outros", também temos a capacidade de construir conhecimento relevante sobre nós mesmos e igualmente sobre o "centro". Qualquer que seja a inclinação, o fato é que esta deve ser uma escolha, uma decisão consciente, ancorada em acesso ao conhecimento, à compreensão de como este foi construído e às possíveis perspectivas alternativas, marginalizadas e até silenciadas. Cabe a nós tomarmos a decisão que melhor nos convém e conforme nossos pressupostos, anseios e expectativas associadas à carreira, seja ela acadêmica ou não. A decisão por alternativas pode ser um primeiro passo para livrar-nos de estruturas e amarras impostas, as quais contribuem para limitar e impedir o livre pensar e a construção de conhecimentos que engrandeçam e fomentem discussões no campo da administração. 


\section{REFERÊNCIAS}

ABDALLA, M. M. Repensando o duplo movimento polanyiano a partir do desenvolvimento de estratégias sociais: um olhar sobre o setor de energia nucleoelétrica à luz da opção decolonial. 305f. 2014. Tese (Doutorado em Administração) - Escola Brasileira de Administração Pública e de Empresas, Fundação Getulio Vargas, Rio de Janeiro, 2014.

ABDALLA, M. M.; FARIA, A. Em defesa da opção decolonial em administração/gestão. Cadernos EBAPE.BR, Rio de Janeiro, v. 15, n. 4, p. 914-929, 2017.

ALCADIPANI, R. Academia e a fábrica de sardinhas. Organizações \& Sociedade, v. 18, n. 54, p. 345-348, 2011 a.

ALCADIPANI, R. Resistir ao produtivismo: uma ode à perturbação acadêmica. Cadernos EBAPE.BR, Rio de Janeiro, v. 9, n. 4, p. 11741178, 2011b.

ALCADIPANI, R.; BERTERO, C. O. Guerra Fria e o ensino do Management no Brasil: o caso da FGV-EAESP. Revista de Administração de Empresas, v. 52, n. 3, p. 284-299, 2012.

ALCADIPANI, R.; BERTERO, C. O. Uma escola norte-americana no Ultramar? Uma historiografia da EAESP. Revista de Administração de Empresas, v. 54, n. 2, p. 154-169, 2014.

ALCADIPANI, R.; BRESLER, R. A. McDonaldização do Ensino. Carta Capital, v. 6, n. 122, p. 20-24, 1999.

ALCADIPANI, R.; CALDAS, M. Americanizing Brazilian management. Critical Perspectives on International Business, v. 8, n. 1, p. 37-55, 2012.

ALCADIPANI, R.; FARIA, A. Fighting Latin American marginality in "international" business. Critical Perspectives on International Business, v. 10, n. 1/2, p. 107-117, 2014.

ALCADIPANI, R. et al. Southern voices in management and organization knowledge. Organization, v. 19, n. 2, p. 131-143, 2012.

ALCADIPANI, R.; ROSA, A. R. From Grobal Management to Glocal Management: Latin American Perspectives as a Counter-Dominant Management Epistemology. Canadian Journal of Administrative Sciences, v. 28, n. 4, p. 453-466, 2011.

ALCADIPANI, R.; ROSA, A. R. O pesquisador como o outro: uma leitura pós-colonial do "Borat" brasileiro. Revista de Administração de Empresas, v. 50, n. 4, p. 371-382, 2010.

BARROS, A. Uma narrativa sobre os cursos superiores em Administração da Face/UFMG: dos primeiros anos à sua unificação em 1968. Cadernos EBAPE.BR, Rio de Janeiro, v. 12, n. 1, p. 7-25, mar. 2014.

BARROS, A.; ALCADIPANI, R.; BERTERO, C. O. A criação do curso superior em Administração na UFRGS em 1963: Uma análise histórica. Revista de Administração de Empresas, v. 58, n. 1, p. 3-15, fev. 2018.

BERTERO, C. O. Ensino e Pesquisa em Administração. São Paulo: Thompson Learning, 2006.

BERTERO, C. O. et al. Os desafios da produção de conhecimento em administração no Brasil. Cadernos EBAPE.BR, Rio de Janeiro, v. 11, n. 1, p. 181-196, mar. 2013.

BOOTH, C.; ROWLINSON, M. Management and organizational history: prospects. Management \& Organizational History, v. 1, n. 1, p. 5-30, 2006.
CLARK, I. Book review: Americanization and its limits: re-working US technology and management in post-war Europe and Japan. Work, Employment and Society, v. 19, n. 2, p. 438-440, 2005.

COELHO, F. S.; NICOLINI, A. M. Revisitando as origens do ensino de graduação em administração pública no Brasil (1854-1952). Revista de Administração Pública, Rio de Janeiro, v. 48, n. 2, p. 367-388, 2014.

COOKE, B. The denial of slavery in Management studies. Journal of Management Studies, v. 40, n. 8, p. 1835-1918, 2003.

COSTA, A. S. M.; BARROS, D. F.; MARTINS, P. E. M. Perspectiva histórica em administração: novos objetos, novos problemas, novas abordagens. Revista de Administração de Empresas, v. 50, n. 3, p. 288-299, 2010.

CZARNIAWSKA, B. Going back to go forward: on studying organizing in action nets. In: HERNES, T.; MAITLIS, S. (Orgs.). Process, sensemaking, \& organizing: perspectives on process organization studies. New York: Oxford University Press, 2010. p. 140-160.

ENGWALL, L. The americanization of Nordic management education. Journal of Management Inquiry, v. 13, n. 2, p. 109-117, 2004.

ESCOBAR, A. Power and visibility: development and intervention and management of the Third World. Cultural Antropology, v. 3, n. 4, p. 428-43, 1988.

FARIA, A.; ABDALLA, M. M. Engajando com o lado mais sombrio do mercado e da gestão. In: ENCONTRO DA ANPAD, 38., 2014, Rio de Janeiro. Anais... Rio de Janeiro: AnPAD, 2014.

FARIA, A.; IBARRA-COLADO, E.; GUEDES, A. Internationalization of management, neoliberalism and the Latin America challenge. Critical Perspectives on International Business, v. 6 n. 2/3, p. 97-115, 2010.

FARIA, A.; WANDERLEY, S. Fundamentalismo da gestão encontra a descolonialidade: repensando estrategicamente organizações familiares. Cadernos EBAPE.BR, Rio de Janeiro, v. 11, n. 4, p. 569587, 2013.

FOSTER, J.; MILLS, J.; MILLS, A. Shades of red: Cold War influences on Canadian and U.S. business textbooks. Journal of Management Education, v. 38, n. 5, p. 642-671, 2014.

FRENKEL, M.; SHENHAV, Y. From Americanization to colonization: the diffusion of productivity models revisited. Organization Studies, v. 24, n. 9, p. 1537-1561, 2003.

GANTMAN, E.; RODRIGUES, C. Notas sobre la evolución del conocimiento administrativo em la República Argentina y su comparación con el caso español (1913-2007). Cadernos EBAPE.BR, v. 6, n. 4, p. 2-22, 2008.

GERSTLE, G. Working-class Americanism: the politics of labour in a textile city, 1914-1960. Cambridge: Cambridge University Press, 1989.

GROSFOGUEL, R. A estrutura do conhecimento nas universidades ocidentalizadas: racismo/sexismo epistêmico e os quatro genocídios/ epistemicídios do longo século XVI. Revista Sociedade e Estado, Brasília, DF v. 31, n. 1, p. 25-49, 2016.

GROSFOGUEL, R. Decolonizing post-colonial studies and paradigms of political-economy: transmodernity, decolonial thinking and global coloniality. Transmodernity: Journal of Peripheral Cultural Production of the Luso-Hispanic World, v. I, n. 1, p. 1-38, 2011. 
GROSFOGUEL, R. Decolonizing Western uni-versalisms: decolonial pluri-versalism from Aimé Césaire to the zapatistas. Transmodernity, v. 2 , n. 1 , p. $88-104,2012$ b.

GROSFOGUEL, R. The epistemic decolonial turn: beyond politicaleconomy paradigms. Cultural Studies, v. 21, n. 2/3, p. 203-246, 2007.

GROSFOGUEL, R. The dilemmas of ethnic studies in the US: between liberal multiculturalism, identity politics, disciplinary colonization, and decolonial epistemologies. Human Architecture - Journal of the Sociology of Self-Knowledge, v. 10, n. 1, p. 9-27, 2012a.

HARAWAY, D. J. Situated Knowledges: The Science Question in Feminism and the Privilege of Partial Perspective. In: HARAWAY, D. (Ed.). Symians, Cyborgs and Women: the Reinvention of Nature. New York: Routledge, 1991[1988]. p. 183-202.

IBARRA-COLADO, E. Organization studies and epistemic coloniality in Latin America: thinking otherness from the margins. Organization, v. 13 , n. 4, p. 463-88, 2006.

IBARRA-COLADO, E.; FARIA, A.; GUEDES, A. L. Introduction to the special issue on "Critical international management and international critical management: perspectives from Latin America". Critical Perspectives on International Business, v. 6, n. 2/3, p. 86-96, 2010.

INSTITUTO NACIONAL DE ESTUDOS E PESQUISAS EDUCACIONAIS ANÍSIO TEIXEIRA - INEP. Sinopse Estatística da Educação Superior 2018. Brasília: Inep, 2019. Disponível em: <http://portal.inep.gov. $\mathrm{br} /$ web/guest/sinopses-estatisticas-da-educacao-superior $>$. Acesso em 20/09/2019.

JACQUES, R. History, historiography and organization studies: the challenge and the potential. Management \& Organizational History, v. 1, n. 1, p. 31-49, 2006.

JACQUES, R. Manufacturing the employee: management knowledge from the 19th to 21st centuries. London: Sage, 1996.

KANBUR, R. The Economics of International Aid. 2003. Disponível em: <http://www.arts.cornell.edu/poverty/kanbur/handbookaid. pdf>. Acesso em: 06 out. 2011.

KELLEY, E.; MILLS, A.; COOKE, B. Management as a Cold War phenomenon? Human Relations, v. 59, n. 5, p. 603-610, 2006.

KHURANA, R. From higher aims to hired hands. New Jersey: Princeton University Press, 2007.

KIESER, A. The americanization of academic management education in Germany. Journal of Management Inquiry, v. 13, n. 2, p. 90-97, 2004.

KIPPING, M.; ENGWALL, L.; ÜSDIKEM. B. Preface: The transfer of management knowledge to peripheral countries. International Studies of Management and Organization, v. 38, p. 4, p. 3-16, 2008/9.

KIPPING, M.; ÜSDIKEN, B.; PUIG, N. Imitation, tension, and hybridization: multiple "Americanizations" of management education in Mediterranean Europe. Journal of Management Inquiry, v. 13, n. 2, 98-108, 2004.

MARCH, J. Parochialism in the evolution of a research community: the case of organization studies. Management and Organization Review, v. 1, n. 1, p. 5-22, 2005.

MCLAREN, P. G.; MILLS, A. J. A product of "his" time? Exploring the construct of the ideal manager in the Cold War era. Journal of Management History, v. 14, n. 4, p. 386-403, 2008.
MIGNOLO, W. Epistemic disobedience, independent thought and de-colonial freedom. Theory, Culture \& Society, v. 26, n. $7 / 8$, p. 1-23, 2009.

MILLS, A.; HATFIELD, J. From imperialism to globalization: internationalization and the management text. In: CLEGG, S.; IBARRACOLADO, E.; RODRIGUEZ, L. (Eds.). Global Management: Universal Theories and Local Realities. London: Sage, 1999.

MIGNOLO, W. Geopolitics of sensing and knowing: on (de)doloniality, border thinking, and epistemic disobedience. Confero, v. 1, n. 1, p. 129-150, 2013.

MIGNOLO, W. The darker side of western modernity: global futures, decolonial options. London: Duke University Press, 2011.

MIR, A. The hegemonic discourse of management texts. Journal of Management Education, v. 27, n. 6, p. 734-738, 2003.

MIR, R.; MIR, A.; SRINIVAS, N. Managerial knowledge as property: the role of universities. Organization Management Knowledge, v. 1, n, 2, p. 126-137, 2004.

MISOCZKY, M.; IMASATO, T. The Brazilian sub-imperialist strategy of regional insertion. Critical Perspectives on International Business, v. 10, n. 4, p. 274-290, 2014.

MITCHELL, T. Colonizing Egypt. Cambridge: Cambridge University Press, 1988.

PAES DE PAULA, A. P. Estudos organizacionais críticos e pensadores nacionais. Cadernos EBAPE.BR, v. 13, n. 3, p. 410-413, 2015.

PAES DE PAULA, A. P. et al. A tradição e a autonomia dos estudos organizacionais críticos no Brasil. Revista de Administração de Empresas, v. 50, n. 1, p. 10-23, 2010.

SAID, E. Orientalism. New York: Pantheon, 1979.

SANTOS, B.; NUNES, J.; MENESES, M. Opening up the canon of knowledge and recognition of difference. In: SANTOS, B. (Ed.). Another knowledge is possible: beyond northern epistemologies. New York: Verso, 2008. p. ixx-Ixii.

SERVA, M. Epistemologia da administração no Brasil: o estado da arte. Cadernos EBAPE.BR, Rio de Janeiro, v. 15, n. 4, p. 741-750, 2017.

SRINIVAS, N. Mimicry and revival the transfer and transformation of management knowledge to India, 1959-1990. International Studies of Management and Organization, v. 38, n. 4, p. 38-57, 2009.

STARBUCK, W. H. The origins of organization theory. In: TSOUKAS, H.; KNUDSEN, C. (Eds.) The Oxford handbook of organization theory: meta-theoretical perspectives. Oxford: Oxford University Press, 2003. p. $143-182$

TIRATSOO, N. The "Americanization" of management education in Britain. Journal of Management Inquiry, v. 13, n. 2, p. 118-126, 2004.

TOTA, A. O Imperialismo Sedutor: A Americanização do Brasil na Época da Segunda Guerra. São Paulo: Cia das Letras, 2000.

ÜSDIKEN, B. Americanization of European Management Education in Historical and Comparative Perspective: A Symposium. Journal of Management Inquiry, v. 13, n. 2, p. 87-89, 2004a.

ÜSDIKEN, B. Exporting managerial knowledge to the outpost penetration of 'Human Relations' into Turkish academia, 1950-1965. Management Learning, v. 35, n. 3, p. 255-270, 2004b. 
seus impactos em decisões na carreira acadêmica em administração

ÜSDIKEN, B; ÇETIN, D. From Betriebswirtschaftslehre to Human Relations: Turkish management literature before and after the Second World War. Business History, v. 43, n. 2, p. 99-124, 2001.

VALE, M. P. E. M. Institucionalização do ensino em administração de empresas na cidade de São Paulo: um estudo de caso sobre a FEA-USP. 144f. 2012. Dissertação (Mestrado em Administração) Escola de Administração de Empresas de São Paulo, Fundação Getulio Vargas, São Paulo.

VAN MAANEN, J. Tales of the field. London: University of Chicago Press, 1988.

VIZEU, F. Potencialidades da análise histórica nos estudos organizacionais brasileiros. Revista de Administração de Empresas, v. 50, n. 1 , p. 36-46, 2010.
WALLERSTEIN, I. Eurocentrism and its avatars: the dilemmas of social science. New Left Review, v. 226, p. 93-108, 1997.

WANDERLEY, S.; FARIA, A. The Chandler-Furtado case: a de-colonial re-framing of a North/South (dis)encounter. Management \& Organizational History, v. 7, n. 3, p. 219-236, 2012.

WESTWOOD, R.; JACK, G. The US commercial-military-political complex and the emergence of international business and management studies. Critical Perspectives on International Business, v. 4, n. 4, p. $367-388,2008$. 